\title{
Cabalistic Rheological \& Thermodynamically Characteristics of Some Naturals Dyes (Experiment for Undergraduate students)
}

\author{
*A. Hassan and S. M. H. Kazmi \\ *Federal Urdu University of Art, Science and Technology, University Road 75300 Karachi, Pakistan, 75300 \\ *Corresponding Author Email: atya007chem@gmail.com
}

\begin{abstract}
Mysterious puissance of temperature on rheology and thermodynamics were studied on three natural dyes. The flowing property of all dyes was also examined at a constant temperature that was $25 \pm 1^{\circ} \mathrm{C}$. Randomness was observed in viscosity at a constant temperature with the variation in concentration. At varying temperatures, the activation energy of Rubus laciniatus and Cinnamon Bark dyes were in negative form indicate that the less probability of collision between the molecules of dyes. Chances of arrangement of all dye molecules are in high order. The activation energy of Purple Cabbage was positive integer while the Gibbs energy of all dyes was in a negative form which divulgement that the reaction of dyes was spontaneous. The statistical treatment was also performed on Viscosity data. Trimmed and winsorized measurement examined outliers of viscosity data.
\end{abstract}

Keywords: Rheology, Thermodynamics, Activation Energy, Gibbs Free Energy, Viscosity,

\section{INTRODUCTION}

Tropical fruits are rich in bioactive compounds and are a great source of colors. Colorants that are obtained from natural sources are known as natural dyes. ${ }^{1}$ The eco-preservation, sustainability, and compatibility of natural colorants make them alpha in the textile industry. Apart from this, the quality of natural dyes in the textile and food industries is of great interest. In processing industries, the flow requirement and original form of fruit juices and dyes are beholden to rheology. ${ }^{2}$ Rheology is used to predict the physical and chemical nature of dyes. The viscosity $(\boldsymbol{\eta})$, Surface tension $(\boldsymbol{\zeta})$, and other drive parameters related to this are affected by the variation in system temperature. The change in such properties of dyes also alters the energy on a molecular level. Variation in energy varies the Gibbs energy ( $\boldsymbol{\Delta} \boldsymbol{G})$, Activation energy $\left(\boldsymbol{E}_{\boldsymbol{0}}\right)$, Entropy $(\boldsymbol{\Delta S})$, and enthalpy $(\boldsymbol{\Delta H})$ of the system. The physical and chemical properties of dyes at the different temperatures on the rheological level are of primary importance.

The literature review revealed that very little work was done on the rheology of natural dyes. The rheology of clarified fruit juices was studied by Ibarz et al. ${ }^{3}$ Rheological properties of sodium alginate and xanthan paste on cotton with reactive dye in screen printing studied by Lili Wang. ${ }^{4}$ Effect of rheology, color, and total phenolic contents of pomegranate juice was studied by H.Yilidiz et al. ${ }^{5}$ Berries are vibrant in color; their phytochemical characterization and evaluation of rheological and antioxidant properties were investigated by Angelo Luis et al. ${ }^{6}$ Similarly, the nonequilibrium thermodynamics and rheology were investigated by $\mathrm{J}$ vehas. ${ }^{7}$. Inspite of the above studies, rheological and physicochemical studied of engine oil by Thapliyal et al. ${ }^{13}$. While shear rate estimation by Kumar et al. ${ }^{14}$ and to find out the rheology of drilling fluids with viscometer done by Liu at $\mathrm{el}^{15}$. Examining of the rheological properties of and statistical correlation of crumb rubber by Mashaan et at ${ }^{16}$, printing pastes by Fijan et at ${ }^{17}$ carrot juice byVandresen ${ }^{18}$, concentrated Guar Gum by Oblons ${ }^{19}$, Beta Carotene in pumpkin puree by Dutta ${ }^{20}$, and colored oil -in water and food emulsion by Batista ${ }^{21}$

The aims and objectives of the current research were to investigate the rheology of three different natural dyes with their statistical treatment. The complex phytochemicals structures and carbohydrates play a crucial role in the variation of rheological properties of natural dyes. These properties can be used to predict the chemical nature of dyes.

\section{EXPERIMENTAL:}

\subsection{Materials}

Rubus laciniatus dye, Cinnamon dye, and purple cabbage dye were used for studying the effect of temperature on rheological properties.

\subsection{Method}

Ostwald U-tube viscometer (Germany) used for noting the rate flow. For the evaporation of solvents, the Rotary evaporator (Buchi Rotavapor R-210) was used.

\subsection{Collection of plant materials}

The Fruits of Rubus laciniatus was collected from North Karachi. The bark of Cinnamon was used for the extraction of dye and collected from the primary market of Alnoor Society located in the central district of Metropolitan of Pakistan. The Purple Cabbage was used to extract dyes and collected from the Imtiaz Super Store near Moti Mehal Karachi. 


\subsection{Preparation of raw materials}

The Fruits of Rubus laciniatus, Bark of Cinnamon, and Purple Cabbage laved by tap water then by distilled water to remove dust particles. The dyes were extracted from all samples at $25 \pm 1^{\circ} \mathrm{C}$.

\subsection{Statistical Treatment}

The different statistical tests were performed on experimental data. The obtained data were subjected to mean deviation (M.D), Standard deviation(S), Trimmed, and winsorized measurements.

\section{RESULT AND DISCUSSION}

\subsection{Viscosity of dyes}

Viscosity, a physical property, can also measure the chemical nature of the liquid substance. The flow rate of every fluid differs from each other due to thickness and variation in the bonding of the analyte. The rate flow of three dyes was examined at constant as well as also at different temperatures. The result of viscosity at $25 \pm 1^{\circ} \mathrm{C}$ was depicted in Table 1. The results showed that the viscosity of Dye 1and 2 was increased with the rise in the concentration of dye solution. The increasing trend in viscosity due to strong electrostatic forces, which leads to increased viscosity. ${ }^{8}$ The unexpected change in the flow rate of the third dye was observed with increased concentration at the constant temperature suggested that the dye contains fewer molecular layers. The viscosity of second dye samples was examined with the reference of water. The viscosity of water at constant temperature $\left(25 \pm 1^{\circ} \mathrm{C}\right)$ was $8.9 \mathrm{dyn}-\mathrm{s} / \mathrm{cm}^{2}$. The viscosity of liquid decreased by the addition of lower viscous liquid and formed a miscible solution with dye. ${ }^{9}$

Table 1:-The Viscosity of Dyes at a constant temperature

\begin{tabular}{|c|c|c|}
\hline \multicolumn{3}{|c|}{ Viscocity $\left(\mathrm{dyn}-\mathrm{s} / \mathrm{cm}^{2}\right)$ at $25^{\circ} \mathrm{C} \pm 1$} \\
\hline Dye $^{1}$ & Dye $^{1}$ & Dye $^{1}$ \\
\hline 8.5 & 8.4 & 8.44 \\
\hline 8.6 & 8.5 & 8.63 \\
\hline 8.7 & 8.5 & 8.63 \\
\hline 8.7 & 8.6 & 8.71 \\
\hline 9.0 & 8.6 & 8.80 \\
\hline 8.9 & 8.8 & 8.71 \\
\hline 8.70 & 9.0 & 8.61 \\
\hline 8.73 & 8.8 & 8.79 \\
\hline 8.80 & 8.9 & 8.89 \\
\hline 9.05 & 9.0 & 8.88 \\
\hline
\end{tabular}

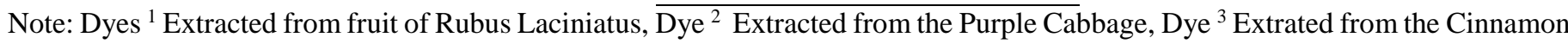
Bark

\subsection{Activation energy}

It is well known that Flow rate has temperature dependence property. The viscosity of dyes at specific temperatures decreased, and the flow rate of dye depends on molecular layers among the molecules. Molecular layers hold together through the rate of friction. When the logarithm of viscosity is plotted against the absolute temperature, the straight line is obtained according to the Arrhenius equations. ${ }^{10}$ The activation energy is the minimum amount of energy required to activate the atoms or molecules to undergo a reaction (Fig- 1). Plotts showed that the activation energy of Dye 1 was $-7.563 \mathrm{kj} / \mathrm{moles}$ while the activation energy for the Dye 2 and 3 were $2.0 \mathrm{Kj} / \mathrm{mole}$ and $14.7 \mathrm{kj} / \mathrm{moles}$, respectively. The negative form of energy for dye 1 was due to a decrease in the probability of active collision. At high temperatures, the rate of some reactions decreased due to ineffective collision. The activation energy of Dye 3 was high among them. The high activation energy of dye 3 suggests the rate sensitivity to temperature, which is similar to the work of representing in (Fig- 3) ${ }^{11}$ The chances of reaction between solvent and dye molecule in dye 3 were meager due to the high energy level. 


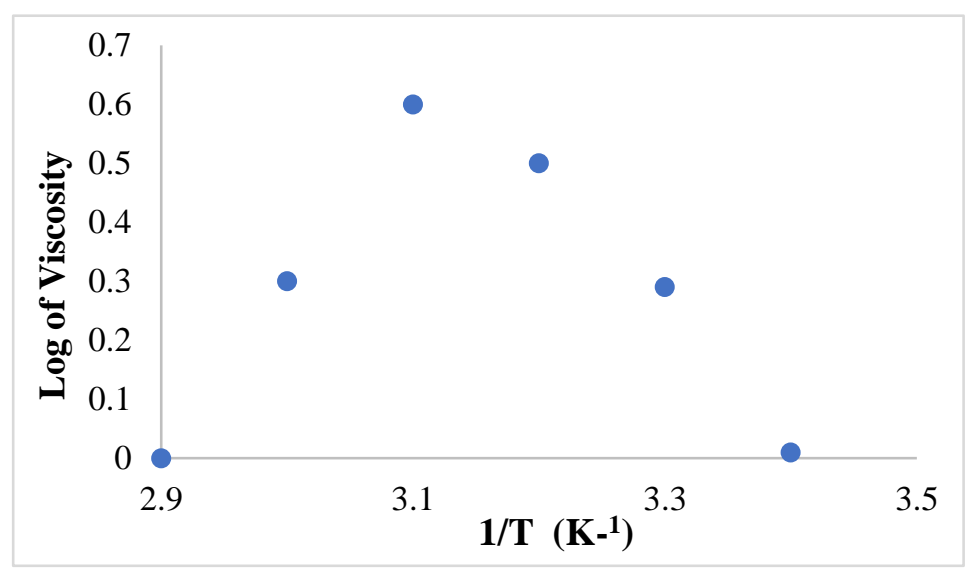

Figure 1: Activation energy as the function of viscosity at different temperature for Dye ${ }^{1}$

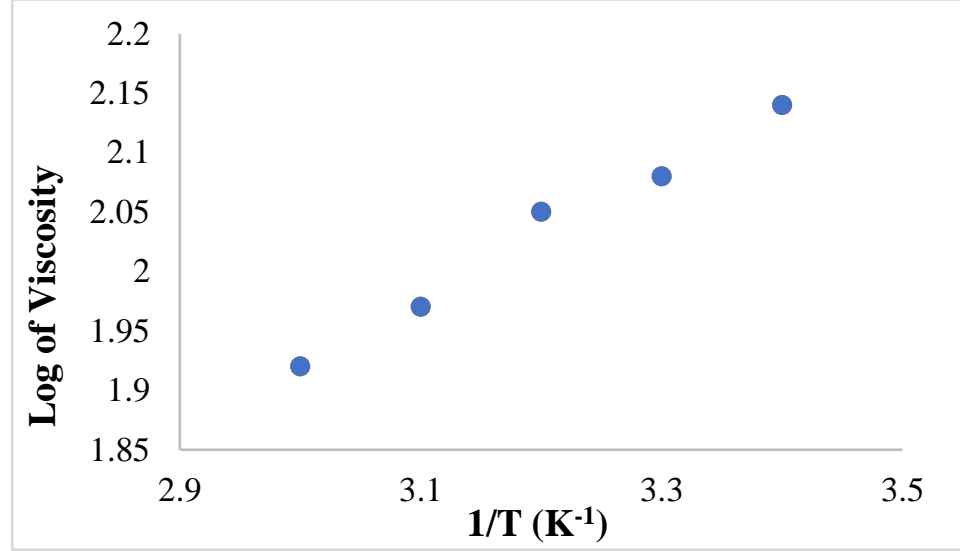

Figure 2: Activation energy as the function of viscosity at different Temperature for Dye ${ }^{2}$

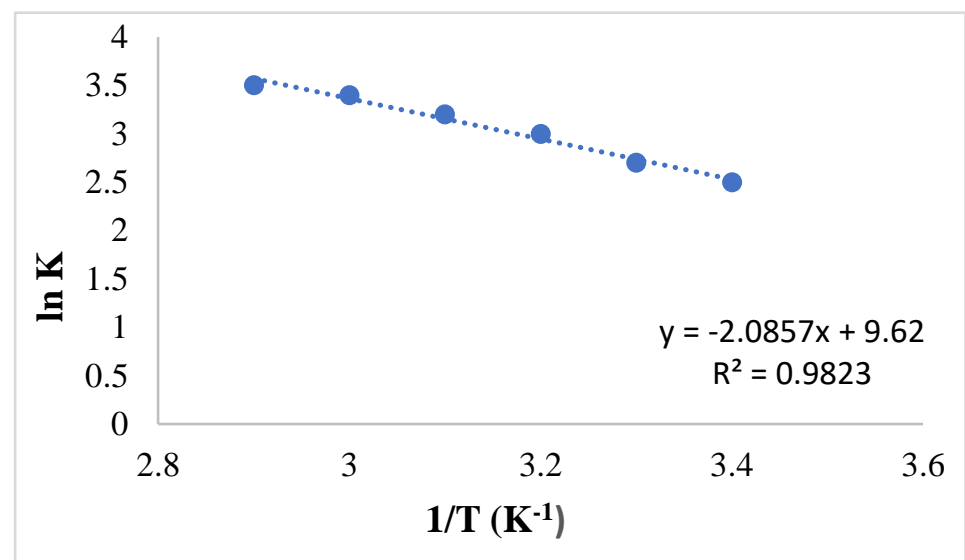

Figure 3: Activation energy as the function of conductance at different Temperature for Dye ${ }^{3}$

The change in one state function also changes the other state functions like the change in temperatures alter the enthalpy, Gibbs free energy, and other properties of dyes. The alteration in thermodynamics functions is used to predict the stability of dye on a molecular level. Basic thermodynamic equations are applied to calculate the change in state functions. The thermodynamic properties of all dye samples under investigation were presented in Table(2), where it was observed that in dye samples, change in Gibbs free energy was spontaneous and feasible.

Table 2: The Thermodynamic functions of different dyes

\begin{tabular}{|c|c|c|c|c|c|}
\hline Samples & $\operatorname{Temp}(K)$ & $\begin{array}{c}\text { Activation Energies } \\
\left(\varepsilon_{A}\right)(\mathrm{KJ} / \mathrm{mole})\end{array}$ & $\begin{array}{c}\text { Enthalpy } \\
(\Delta H)(\mathrm{KJ} / \mathrm{mole})\end{array}$ & $\begin{array}{c}\text { Entropy } \\
(\Delta S)(\mathrm{KJ} / \text { mole.k }) \\
\end{array}$ & $\begin{array}{c}\text { Gibbs energy } \\
(\Delta G)(\mathrm{KJ} / \mathrm{mole})\end{array}$ \\
\hline \multirow{2}{*}{ Dye 1} & 283 & -2.5 & -4.8 & $9.5 \times 10^{-3}$ & -7.5 \\
\hline & 293 & -3.1 & -5.5 & $7.4 \times 10^{-3}$ & -7.7 \\
\hline
\end{tabular}




\begin{tabular}{|c|c|c|c|c|c|}
\hline & 303 & -2.5 & -5.0 & $9.9 \times 10^{-3}$ & -8.0 \\
\hline & 313 & -1.96 & -4.5 & $12.1 \times 10^{-3}$ & -8.3 \\
\hline & 323 & -1.5 & -4.1 & $13.6 \times 10^{-3}$ & -8.5 \\
\hline \multirow{5}{*}{ Dye 2} & 283 & 3.827 & 1.47 & $15.8 \times 10^{-3}$ & -3.00 \\
\hline & 293 & 3.943 & 1.50 & $15.6 \times 10^{-3}$ & -3.09 \\
\hline & 303 & 3.940 & 1.42 & $15.2 \times 10^{-3}$ & -3.20 \\
\hline & 313 & 3.856 & 1.25 & $14.5 \times 10^{-3}$ & -3.31 \\
\hline & 323 & 3.856 & 1.17 & $14.1 \times 10^{-3}$ & -3.41 \\
\hline \multirow{5}{*}{ Dye 3} & 283 & -6.57 & -8.92 & 0.03 & -20.2 \\
\hline & 293 & -6.23 & -8.66 & 0.04 & -20.9 \\
\hline & 303 & -5.99 & -8.51 & 0.04 & -21.6 \\
\hline & 313 & -5.78 & -8.38 & 0.04 & -22.3 \\
\hline & 323 & -5.56 & -8.14 & 0.05 & -23.0 \\
\hline
\end{tabular}

\subsection{Statistical treatments}

Basic statistical tests were applied to find the numerical fact of data. The arithmetic mean of deviations from the mean for the three (under investigation) sets of data is mean deviation. The result reported in Table 3 for dyes is an absolute deviation from the mean of the data set for dyes. The mean deviation calculates through equation 1.

$$
\text { M.D }=\sum\left|\mathbf{X}_{\mathbf{i}}-\mathbf{X}_{\mathbf{m}}\right| / \mathbf{n} \ldots . . . .1
$$

The $\left|\mathbf{X}_{\mathbf{i}}-\mathbf{X}_{\mathbf{m}}\right|$ was indicated that the absolute deviation of the observation from the mean of a sample. The average spread around the mean was examined via equation 2 .

$$
S^{2}=\sum\left|X_{i}-X_{m}\right|^{2} / \mathbf{n} \ldots . . .2
$$

While $\mathrm{S}$ is the standard deviation. The positive root square of variance. The M.D for the Dye 1 was 0.134 , and the Standard deviation was 0.162 .

\begin{tabular}{|c|c|c|c|c|}
\hline Samples & $\begin{array}{c}X_{i} \\
\text { dyn-s/cm } \\
\end{array}$ & $\mathbf{X}_{\mathbf{i}}-\mathbf{X}_{\mathbf{m}}$ & $\left|\mathbf{X}_{\mathbf{i}}-\mathbf{X}_{\mathbf{m}}\right|$ & $\left|X_{i}-X_{m}\right|^{2}$ \\
\hline \multirow{10}{*}{ Dye 1} & 8.5 & -0.26 & 0.26 & 0.067 \\
\hline & 8.6 & -0.16 & 0.16 & 0.025 \\
\hline & 8.7 & -0.06 & 0.06 & 0.0036 \\
\hline & 8.7 & -0.06 & 0.06 & 0.0036 \\
\hline & 9.0 & 0.24 & 0.24 & 0.057 \\
\hline & 8.9 & 0.14 & 0.14 & 0.019 \\
\hline & 8.7 & -0.06 & 0.06 & 0.0036 \\
\hline & 8.73 & -0.03 & 0.03 & 0.0009 \\
\hline & 8.80 & 0.04 & 0.04 & 0.0016 \\
\hline & 9.05 & 0.29 & 0.29 & 0.084 \\
\hline \multirow[t]{7}{*}{$\sum$} & 8.76 & - & 1.34 & 0.265 \\
\hline & 8.4 & -0.31 & 0.31 & 0.0961 \\
\hline & 8.5 & -0.21 & 0.21 & 0.0441 \\
\hline & 8.5 & -0.21 & 0.21 & 0.0441 \\
\hline & 8.6 & -0.11 & 0.11 & 0.0121 \\
\hline & 8.6 & -0.11 & 0.11 & 0.0121 \\
\hline & 8.8 & 0.09 & 0.09 & 0.0081 \\
\hline \multirow[t]{4}{*}{ Dye 2} & 9.0 & 0.29 & 0.29 & 0.0841 \\
\hline & 8.8 & 0.09 & 0.09 & 0.0081 \\
\hline & 8.9 & 0.19 & 0.19 & 0.0361 \\
\hline & 9.0 & 0.29 & 0.29 & 0.0841 \\
\hline \multirow[t]{4}{*}{$\sum$} & 8.71 & - & 1.90 & 0.429 \\
\hline & 8.44 & -0.269 & 0.269 & 0.0723 \\
\hline & 8.63 & -0.079 & 0.079 & 0.0062 \\
\hline & 8.63 & -0.079 & 0.079 & 0.0062 \\
\hline
\end{tabular}

Table 3. The statistical treatment of viscosities of different dyes 


\begin{tabular}{ccccc} 
Dye 3 & 8.71 & 0.001 & 0.001 & 0.000001 \\
& 8.80 & 0.091 & 0.091 & 0.0082 \\
8.71 & 0.001 & 0.001 & 0.000001 \\
8.61 & -0.099 & 0.099 & 0.0098 \\
8.79 & 0.081 & 0.081 & 0.0065 \\
& 8.89 & 0.181 & 0.181 & 0.032 \\
& 8.88 & 0.171 & 0.171 & 0.029 \\
\hline$\sum$ & $\mathbf{8 . 7 0 9}$ & - & $\mathbf{1 . 0 5 2}$ & $\mathbf{0 . 1 7 0}$ \\
\hline
\end{tabular}

Note: The absolute measure of dispersion for dye 2 was 0.19 , while the coefficient of M.D was 0.02. S.D was 0.207 . The M.D of dye 3 was 0.12 , and the Square root of variance was 0.02 .

\subsection{Wild Observations (Trimmed and Winsorized Measurements)}

Different value (extreme or lowest) from the data or observation was incorrect. This extreme observation was wild observation and, in statistical language, is an outlier. Outliers can cause a problem during data analysis. Trimmed and Winsorized measurement is used to study the wild observation. The removal of a certain percentage of small or large observations is so-called Trimmed data. The replacement of trimmed value by those following in magnitude to obtained is winsorized data (proposed by C.P Winsor ).

Table. 4: Wild observation of Viscosities of Three Dyes

\begin{tabular}{cccccccc}
\hline Samples & Median & $\begin{array}{c}\text { Quartile } \\
\text { Q1 }\end{array}$ & $\begin{array}{c}\text { Quartile } \\
\text { Q3 }\end{array}$ & $\begin{array}{c}\text { Trimmed } \\
\text { Mean }\end{array}$ & $\begin{array}{c}\text { Trimmed } \\
\text { S.D }\end{array}$ & $\begin{array}{c}\text { WinsoRized } \\
\text { Mean }\end{array}$ & $\begin{array}{c}\text { Winsorized } \\
\text { S.D }\end{array}$ \\
\hline Dye 1 & 8.71 & 8.70 & 8.9 & 8.75 & 3.91 & 8.77 & 0.06 \\
Dye 2 & 8.7 & 8.5 & 8.9 & 8.70 & 3.89 & 8.70 & 0.02 \\
Dye 3 & 8.71 & 8.6 & 8.8 & 8.71 & 0.17 & 8.70 & 0.07 \\
\hline
\end{tabular}

The trimmed means were obtained from the viscosity data of three dyes by removing all observations below and after the first and third quartile, respectively. Below and after the first and third quartile, the data was modified to obtain a Winsorized mean.

\section{CONCLUSION}

The Shear rate of three dyes under share stress was in disordered forms. Concentration act here as shared stress. The activation energy of dye $1 \& 3$ molecules is in negative form, indicating that the less probability of collision among the molecules while the activation energy of dye 2 was in positive form. The spontaneity of reaction to be accountable to Gibbs energy. The Gibbs energy of all dyes was in a negative form which indicates that the reaction is feasible.

\section{ACKNOWLEDGMENT}

The author would like to thank the Department of Chemistry Federal Urdu University of Arts, Science, and technology for providing this facility for this research work.

\section{REFERENCES}

1. Emanuela Flor De.V., Andre.J., Simone H.F., Alessandro De O.R., (2015), J. Food Processing and preservation, 41(1)., 1-8.

2. Sheringari, S., M., Pakalapati, S., R., Amrinder, S., B., J.Food.Sci. (2012), 30, 456-466.

3. Ibarz, A., Pagan, J., Miguelsanz, R. J. Food Eng., (1992), 15, 63-73.

4. Lili. W., Furong. Z., Danian.L., (2015), J. Textile Research., 83(17), 1873-1884.

5. Yildiz, H., Bozkurt, H., Icier, F. İ. L. İ. Z. Food Science and Technology International, (2009), 15, 503-512.

6. Angelo.L., Sonia.S., Ana paula.D., Luisa.P., Fernanda.D., (2018), J. Berry research., 8(1)., 11-23.

7. Verhás, J. Prog. Trends Rheol. V, Proc. Eur. Rheol. Conf., 5th, (1998), 124-126.

8. Fareghi-Alamdari, R., Hatefipour, R., J. Mol. Liq. (2017), 225, 793-799.

9. Chaban, V., Fileti, E. J. Phys. Chem. B (2015), 199, 3824-3828.

10. Saravacos, G. D. J. Food Sci., (1970), 35, 122-125. 
11. Atkins, P., de Paula, J., (2011), Physical chemistry for the life science., The kinetics of life process part 2 Chapter 06, $2^{\text {nd }}$ edition., PP 236., ISBN- 13: 978-1-492-3114-5, ISBN-10:1-2492-3114-9.

12. Thapliyal, P., Thakre, G. D. Adv. Tribol., (2017) Article ID 1257607.

13. Kumar,V., Guria, C. J. Pet. Sci. Eng., (2013), 110, 162-168.

14. Liu, K., Qui, Z., Luo, Y., Liu, Y., Zhou, G. Drilling Fluid I: Completion Fluid, (2014), 31, 60-62.

15. Mashaan, N. S., Karim, M. R., Mater. Res., (2012), 16, 116-127.

16. Fijan, R., Basile, M., Lapasin, R., Turk, S. S., Carbohydr. Polym., (2009), 78, 25-35.,

17. Vandresen, S., Quadri, M. G. N., de Souza, J. A. R., Hotza, D., J. Food Eng., (2009), 92, 269-274.

18. Oblons, M., Sostar-Turk, S., Lapasin, R., Rheol. Acta., (2003), 42: 491-499,

19. Dutta, D., Dutta, A., Raychaudhuri, U., Chakraborty, R., J. Food Eng. (2006), 76, 538-546.

20. Batista, A. P., Raymundo, A., Sousa, I., Empis, J., Food Hydrocolloids. (2006), 20, 44-52. 